Proceedings

\title{
Impact of Strain Aging Kinetics on the Failure of Thin Steel Wire Ropes ${ }^{\dagger}$
}

\author{
Tamás Bálint Mező ${ }^{1, *}$ and Péter Barkóczy ${ }^{2}$
}

Citation: Tamás Bálint Mező; Péter Barkócz Impact of Strain Aging Kinetics on the Failure of Thin Steel Wire Ropes. 2021, 3, x. https://doi.org/10.3390/xxxxx

Published: 22 February 2021

Publisher's Note: MDPI stays neutral with regard to jurisdictional claims in published maps and institutional affiliations.

Copyright: $@ 2021$ by the authors. Submitted for possible open access publication under the terms and conditions of the Creative Commons Attribution (CC BY) license (http://creativecommons.org/licenses /by/4.0/).
1 Institute of Physical Metallurgy, Metal Forming and Nanotechnology, University of Miskolc, 3515 Miskolc, Hungary; tamas.mezo81@gmail.com

2 Institute of Physical Metallurgy, Metal Forming and Nanotechnology, University of Miskolc, 3515 Miskolc, Hungary; fembarki@uni-miskolc.hu

* Correspondence: tamas.mezo81@gmail.com; Tel.: +36-202122822

+ Presented at The 1st International Electronic Conference on Metallurgy and Metals (IEC2M), 22 February 7 March 2021

\begin{abstract}
Under quasi-static loading an irregular failure mode of high strength thin carbon steel cords were observed after low temperature thermal aging. Character and kinetics of damage in such wire ropes highly depend on the plastic elongation of the steel wires, which is significantly modified by the strain aging effect. In this paper the static strain aging effect on heavily drawn high-carbon steel wires and their cords is experimentally studied in the $100-200{ }^{\circ} \mathrm{C}$ temperature range. Quantitative analysis of the affected strength and strain parameters is given. Kinetics of the aging process is discussed, and based on this, the macroscopic failure mechanism is fundamentally explained.
\end{abstract}

Keywords: strain aging; drawn steel wire; wire rope; steel cord

\section{Introduction}

One of the most interesting applications of strands made of high strength steel wires is the reinforcement of high-pressure flexible pipes. The strands are embedded in rubber when they are being built into the layered hose structure (Figure 1). These types of flexible pipes are typically used in the oil industry, where they can be exposed to extremely high pressure up to more than $300 \mathrm{MPa}$ [1]. The design of the structure of the hose and the determination of its properties are complex tasks. Some of the basic design parameters are the mechanical characteristics of the strands, and their behavior under axial loads. Due to the extreme conditions, all phenomena must be known and studied that may affect the mechanical properties of the steel cords [2].

The reinforcement cords can be built up from wires of the same, or different diameters. The behavior of the strands is primarily determined by the properties of the single wires and the stranding parameters (e.g. number of wires, construction, lay directions and lay lengths) [3]. In this case the main design parameters that need to be taken into consideration are the ultimate tensile strength, yield strength, elongation at break and the elastic modulus of the wire ropes. The safe operation of the hoses relies on the proper determination of these values.

The wires are made of high carbon $(0.8-0.9 \mathrm{w} \%)$ steel. The high strength is provided by the fine pearlitic structure and the cold deformed state. The resulting tensile strength of this type of wires is larger than $2000 \mathrm{~N} / \mathrm{mm} 2$. Strain ageing is a typical process in cold deformed steel, where tensile strength is increasing, however, elongation decreases $[4,5]$. Strain ageing has been a researched phenomenon for a long time. The cold plastic deformation increases the number of dislocations in the deformed metallic lattice [6]. The interstitial elements, mainly carbon in this case, diffuse into the affected zone of the dis- 
locations. Therefore, the further movement of these dislocations becomes obstructed [4]. Diffusion is a slow process hence strain aging requires time [7].

Diffusion is strongly affected by temperature. The diffusion of the carbon in steel is more intensive at high temperature. Therefore, strain aging becomes faster at elevated temperatures [8]. Relevant literature mentions that at temperature higher than $200^{\circ} \mathrm{C}$ the excess carbon from the decomposition of iron-carbide also affects the kinetics of strain ageing [9].

Alloying and carbon content have primary effect on the kinetics of strain aging. Due to the role of carbon atoms, the effect of carbon content is trivial. However, other elements differ in their effect on carbon solubility and carbon diffusion [10]. For this reason, composition is important in the study of strain ageing, as is the degree of plastic deformation. The degree of deformation influences the dislocation density, and as a result, influences the aging process.

Dynamic strain aging (DSA) and static strain ageing (SSA) processes are distinguished in the literature. DSA takes place mainly during severe plastic deformation or during deformation at elevated temperatures [11]. In the case of the aforementioned wires, SSA has a significant impact on the mechanical properties.

The embedding of strands into rubber layers is followed by the vulcanization procedure at around $150{ }^{\circ} \mathrm{C}$. This temperature is high enough to start, or even to complete the strain ageing process of the wires. Therefore, the mentioned mechanical parameters of the cords are also modified. If SSA process is taken in account, the tensile strength of the wires, hence the strength of the whole strand will increase while the elongation of the wires, thus the elongation of the whole strand will decrease.

A stranded structure is properly designed if the wires can work together during the application particularly under axial loading [3]. One of the basic requirements is to avoid significant variation in strength and elongation. Normally this can be examined well before the embedding and vulcanization process. The main question is how significant is the change that happens in the most important properties during the heat treatment, and whether these changes are uniform from wire to wire, or not. This question is highly important in the case of steel cords that contain wires with different diameters. Another relevant question to be answered is how the damage of the strands is affected by SSA.

In this study we are looking for the answer to the questions raised above. For this reason, high-carbon steel wires-with specific diameter, chemical composition and strength-and two different types of steel strands (Warrington and compact) that are specifically used as reinforcement materials for high-pressure oil hoses are investigated. The effect of SSA on the single wires is examined as a function of time and temperature. In addition, the exact magnitude of change in mechanical properties of the cords is determined. Based on the results appropriate parameters for cord as well as the whole flexible pipe designs are suggested.

Moreover, an irregular failure mode of Warrington type cords is reported. This premature fracture is found in aged conditions and the mechanism of the damage is investigated. Finally, consequences to engineering applications and their resolutions are discussed. 


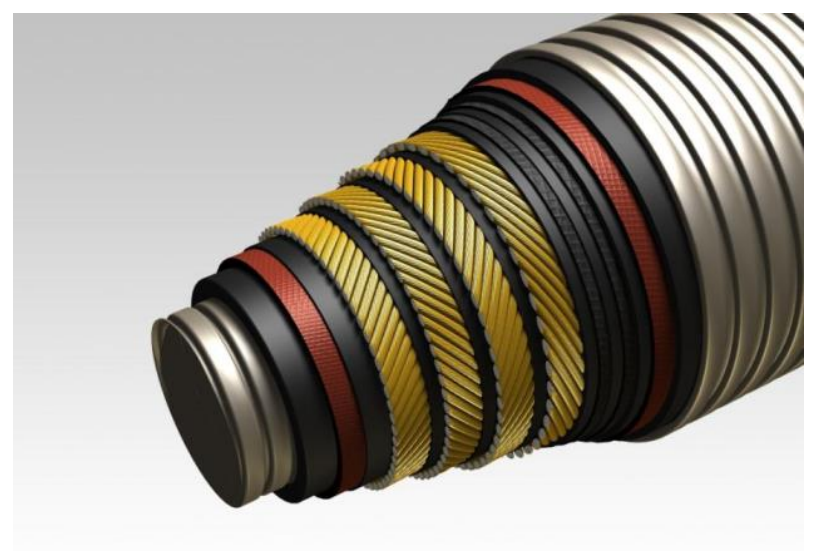

Figure 1. Typical structure of a high-pressure oil hose [1].

\section{Materials and Methods}

Commercial grade cold drawn high strength high-carbon steel wires and steel cords made of them were investigated. The chemical composition of the wires can be seen in Table 1.

Table 1. Chemical analysis of the wire steel (w\%)

\begin{tabular}{cccccc}
\hline & C & Mn & Si & P & S \\
\hline Ø0.71; Ø0.76 & 0.83 & 0.53 & 0.35 & 0.008 & 0.009 \\
Ø0.68; Ø0.91 & 0.88 & 0.57 & 0.21 & 0.009 & 0.008 \\
\hline
\end{tabular}

Nominal yield strength at $0.2 \%$ plastic strain offset $\left(R_{p 02}\right)$ and coating type of the wires are given in Table 2.

Table 2. Nominal yield strength and coating type of the wires

\begin{tabular}{ccc}
\hline & $\mathbf{R}_{\mathbf{p 0 2}}\left(\mathbf{N} / \mathbf{m m}^{2}\right)$ & Coating \\
\hline$\varnothing 0.71$ & 1960 & $67 \% \mathrm{Cu} / 33 \% \mathrm{Zn}$ \\
$\varnothing 0.76$ & 1760 & $67 \% \mathrm{Cu} / 33 \% \mathrm{Zn}$ \\
$\varnothing 0.68$ & 1960 & $\mathrm{Zn}$ \\
$\varnothing 0.91$ & 1760 & $\mathrm{Zn}$ \\
\hline
\end{tabular}

Two types of steel cords composed of these wires were examined (Table 3). The relatively simple structure of Ø3.6C cord represents the class of compact strands mainly built up from equal filaments. The more complex $\varnothing 4.5 \mathrm{~W}$ cord falls in the category of Warrington cords. Both types of cords are mostly used as main reinforcement of high-pressure oil \& gas rubber hoses.

Table 3. Nominal maximum force and structure of steel cords

\begin{tabular}{ccc}
\hline & $\mathbf{F}_{\max }(\mathbf{N})$ & Structure \\
\hline$\varnothing 3.6 \mathrm{C}$ & 18000 & $1 * \varnothing 0.76+6 * \varnothing .71+12 * \varnothing 0.71$ \\
$\varnothing 4.5 \mathrm{~W}$ & 27000 & $3 * \varnothing 0.68+7 * \varnothing .91+(7 * \varnothing 0.68+7 * \varnothing 0.91)$ \\
\hline
\end{tabular}

Samples of $\varnothing 0.71$ wire for kinetic investigation were artificially aged in hot air at temperatures $80{ }^{\circ} \mathrm{C}, 100{ }^{\circ} \mathrm{C}, 125^{\circ} \mathrm{C}, 150{ }^{\circ} \mathrm{C}, 180{ }^{\circ} \mathrm{C}$ and $200{ }^{\circ} \mathrm{C}$. Continuous air ventilation ensured temperature control with an accuracy of $+/-1^{\circ} \mathrm{C}$ with transient periods less than 10 sec. At each temperature, a minimum of 6 different aging periods were applied from 3 min to $729 \mathrm{~min}$. For temperatures $80-125{ }^{\circ} \mathrm{C}$ additional heat treatment periods were added up 
to $59049 \mathrm{~min}$. Specimens in as-drawn condition were also retained as control groups. All samples were taken from the same drawing batch and stored for no longer than 30 days before preparation and testing. The storage temperature was kept below $10{ }^{\circ} \mathrm{C}$ to mitigate the impact of any unintended early aging.

In order to gain quantitative information about the impact of SSA on the mechanical parameters, steel cord specimens from both $\varnothing 3.6 \mathrm{C}$ and $\varnothing 4.5 \mathrm{~W}$ types were heat treated at $150{ }^{\circ} \mathrm{C}$ for $45 \mathrm{~min}$. The sample sizes were 315 and 76 respectively with the same numbers of pieces kept intact as control groups.

Load-elongation curves were determined via tensile testing at room temperature at a constant load rate of $40 \mathrm{~N} / \mathrm{s}$. Elongation was measured with an optical extensometer. Maximum force $\left(\mathrm{F}_{\max }\right)$, force at yield - taken at $0.2 \%$ plastic strain offset- $\left(\mathrm{F}_{02}\right)$, total elongation at break $(\varepsilon)$ and its purely plastic component $\left(\varepsilon_{\mathrm{p}}\right)$ were evaluated. It is noted that in the case of the investigated high strength materials $F_{\max }$ is the same as the force at break. Characterizing steel wires ultimate tensile strength $\left(R_{m}\right)$ and yield strength $R_{p 02}$ are more conventional thus they are calculated from the directly measured relevant forces $F_{\max }$ and F02 respectively.

\section{Results and Discussion}

\subsection{Kinetic character of static strain aging effect on wires}

The yield strength of $\varnothing 0.71$ wire is determined after isothermal aging at temperature levels in the $80-200^{\circ} \mathrm{C}$ range and also at untreated as-drawn condition (Figure 2). The length of the applied heat treatment periods are exponentially extended starting from 3 min. Each dot in Figure 2 represents the mean value of three independent measurements.

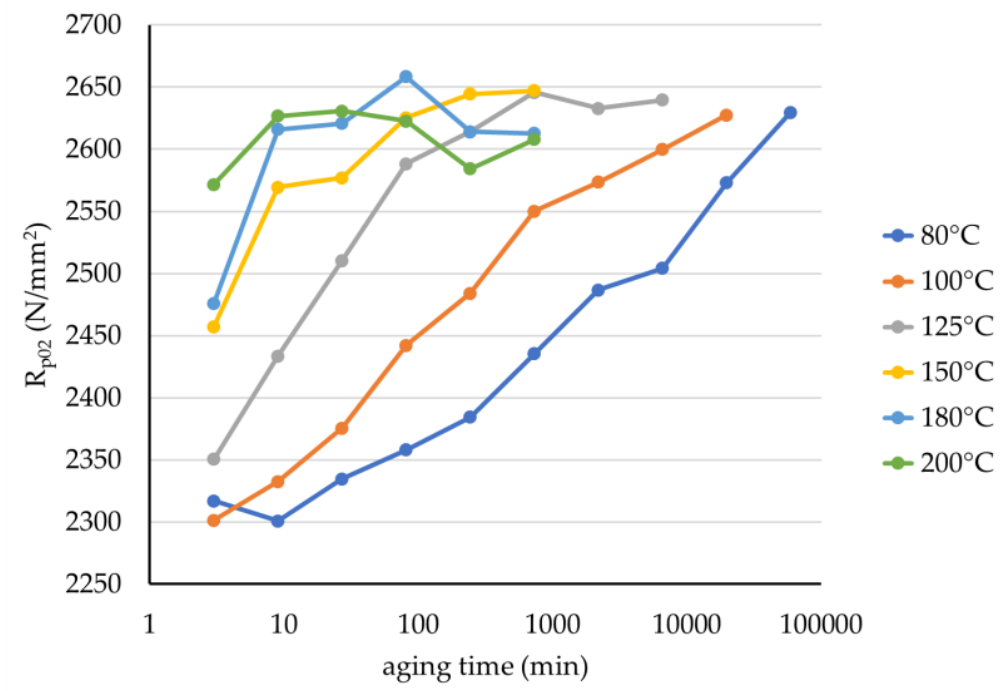

Figure 2. Yield strength vs. aging time ( $\varnothing 0.71$ wire, $80-200{ }^{\circ} \mathrm{C}$ )

A significant and generally steady increase is found in $\mathrm{R}_{\mathrm{p} 02}$ as the aging time is prolonged at each treatment temperature. The tendency becomes sharper as the aging temperature is raised. The saturation character of the trend is obvious above $100{ }^{\circ} \mathrm{C}$ as $R_{p 02}$ attains maximum in the $2570-2650 \mathrm{~N} / \mathrm{mm}^{2}$ interval from the initial average value of 2300 $\mathrm{N} / \mathrm{mm}^{2}$. Under $80-100{ }^{\circ} \mathrm{C}$ aging conditions the same effect is presumable however to make it visible even longer heat treatment time is required.

The exact same process character is found for $R_{m}$ with an initial value of 2540 $\mathrm{N} / \mathrm{mm}^{2}$, which is gradually rising and finally stabilizes in the $2640-2680 \mathrm{~N} / \mathrm{mm}^{2}$ range. This presents a total change of $\mathrm{R}_{\mathrm{m}}$ caused by SSA around one third that it can be seen for $\mathrm{R}_{\mathrm{p} 02 .}$ 
From tensile diagrams total elongation $\varepsilon$ is recorded, then by simple separation from the linear part the pure plastic strain $\varepsilon_{\mathrm{p}}$ is determined. As opposed to the steady increase in strength, monotonous decline is observed as the treatment time prolongs in the cases of all of the aging temperatures previously applied (Figure 3). Stabilization of plastic strain capacity of the material is apparent for aging temperatures $125-200{ }^{\circ} \mathrm{C}$. Ultimate $\varepsilon_{\mathrm{p}}$ values are as low as $0.2-0.25 \%$. Just like in the case of the strength properties this is still to be proven for aging conditions at or below $100{ }^{\circ} \mathrm{C}$. Nevertheless, plummeting from the original $0.7 \%$ figure makes overall plastic strain the parameter that is particularly affected by SSA. It is noticed that the difference between final $R_{p 02}$ and $R_{m}$ values are almost negligible, which matches the minimal $\varepsilon_{\mathrm{p}}$ value found after long term heat treatment.

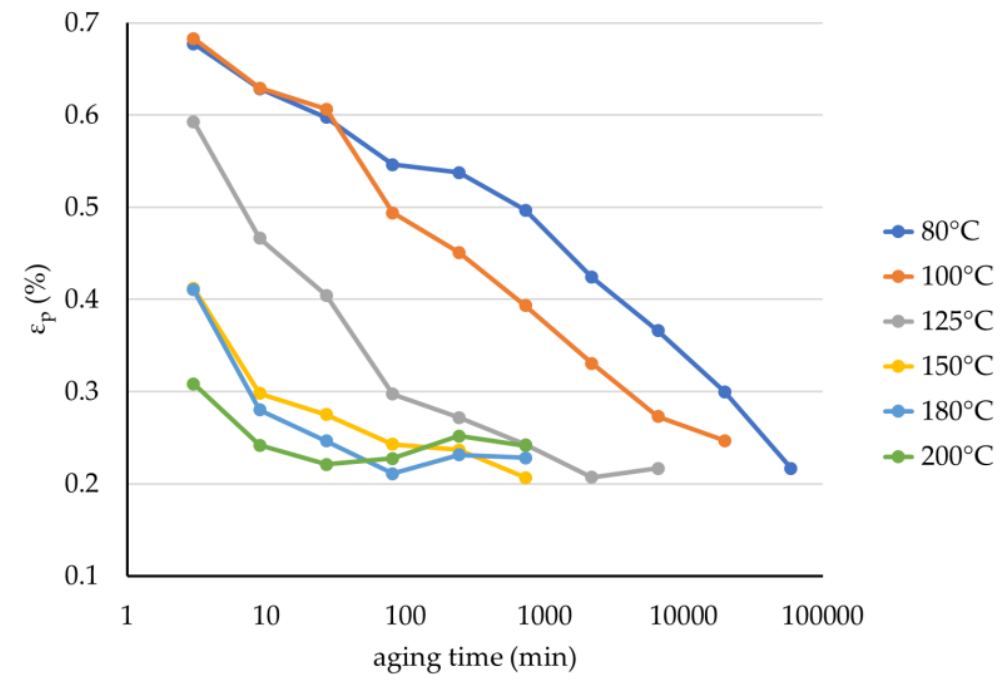

Figure 3. Plastic strain vs. aging time ( $\varnothing 0.71$ wire, $80-200{ }^{\circ} \mathrm{C}$ )

\subsection{Quantitative investigation of SSA effect on compact steel cords with large sample size}

For a quantitative description of the change in the relevant mechanical parameters, Ø3.6C compact type steel cord is investigated with sample size of 630. Due to the fact, that $Ø 3.6 \mathrm{C}$ consists of nearly the same type of wires, general conclusions can directly be linked to the material of the base filament.

Half of the specimens were tensile tested in untreated condition with the other half tested being previously subjected to aging at $150{ }^{\circ} \mathrm{C}$ for $45 \mathrm{~min}$. Based on the findings discussed in the preceding subsection it is considered that SSA has entirely concluded in case of the treated half of the sample. In this manner results displayed in Table 4 describes the total change in the given material parameters and the related standard deviation (SD) as the aging effect takes place and ultimately reaches stabilized saturation.

In the case of steel cord reinforced rubber hoses - the main application area of the examined cords-the vulcanization temperature is typically around $150{ }^{\circ} \mathrm{C}$. For this reason, the effect of SSA phenomenon is of special interest in this condition.

Table 4. Strength and strain parameters of $Ø 3.6 \mathrm{C}$ compact steel cord in untreated and aged conditions

\begin{tabular}{cccccc}
\hline & & $\mathbf{F}_{\mathbf{0 . 2}}(\mathbf{N})$ & $\mathbf{F}_{\max }(\mathbf{N})$ & $\varepsilon(\%)$ & $\varepsilon_{\mathrm{p}}(\mathbf{\%})$ \\
\hline \multirow{2}{*}{ untreated } & mean & 16655 & 18735 & 2.591 & 1.168 \\
& SD & 409 & 209 & 0.128 & 0.131 \\
\hline \multirow{2}{*}{ aged $^{*}$} & mean & 19598 & 20095 & 1.845 & 0.379 \\
& SD & 323 & 220 & 0.061 & 0.063 \\
\hline
\end{tabular}

* $150{ }^{\circ} \mathrm{C} / 45 \mathrm{~min}$ 
Mean strength and its modification correlate very well with the values gained from measurements on the filaments that were introduced in the previous subsection. This fact confirms the relevancy of results derived from the examination of these simple steel cords for the base wire materials. The accuracy of the measurements is reflected in standard deviation magnitudes below $2.5 \%$.

The falling tendency in elongation with increasing aging time is also associated with the discussed kinetics of SSA of wires. Nevertheless, in case of Ø3.6C compact steel cord the average $\varepsilon_{\mathrm{p}}$ is approximately two times greater than in case of its $\varnothing 0.71$ component wire. The same ratio is found both in untreated as well as in aged conditions. This may originate in the well-known structural elongation of cords that affects strain properties under axial loading in addition to the homogenous deformation of the base material [2].

Histograms are used to visualize the data of aged and basic conditions in terms of $\mathrm{F}_{02}$ and $\mathrm{F}_{\max }$ in Figure 4 furthermore $\varepsilon$ and $\varepsilon_{\mathrm{p}}$ in Figure 5.

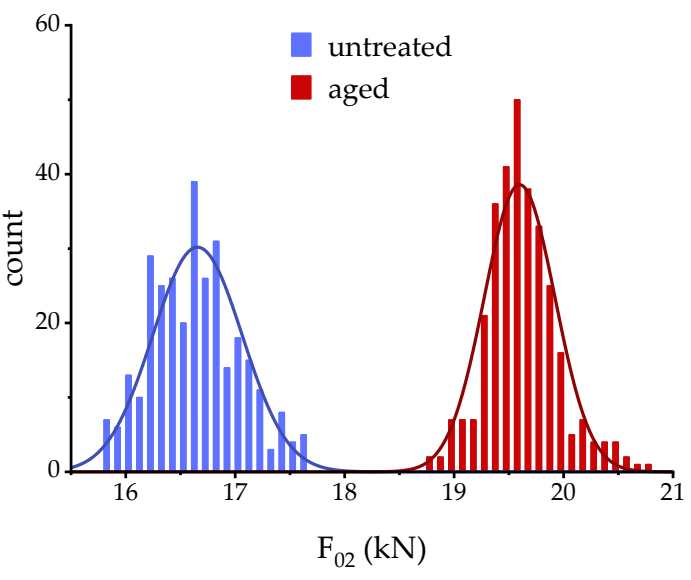

(a)

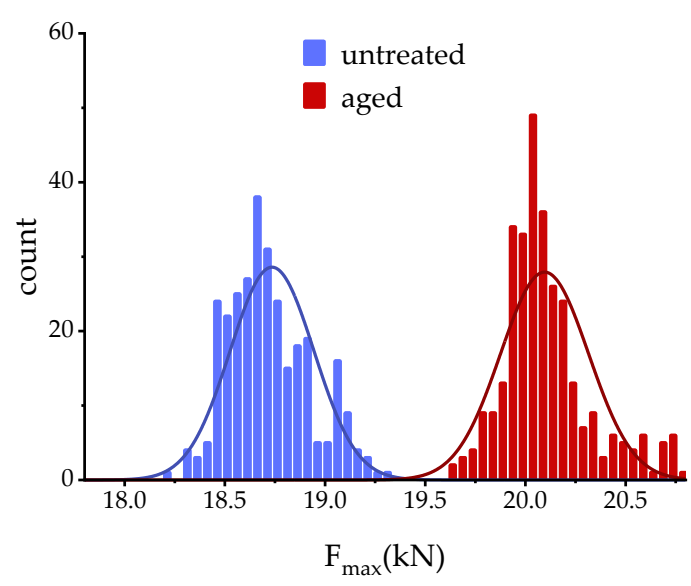

(b)

Figure 4. Histograms of (a) force at yield and (b) maximum force for $\varnothing 3.6 \mathrm{C}$ compact steel cord in untreated and $150{ }^{\circ} \mathrm{C} /$ 45 min aged conditions

Populations of untreated and aged samples are obviously separated, and distributions can be very well approximated by Gaussians. Function parameters can be found in Table 2, where the SD is the square root of the actual variance.

Noticeable differences in distribution profiles are found as the total elongation is compared to the plastic elongation. In theory if the elastic modulus was not affected by aging the mentioned profile shape would match more precisely. Beside measurement inaccuracy the seen deviation may be caused by a slight variation in Young moduli caused by SSA. This subject is out of the scope of present work and requires further research. 


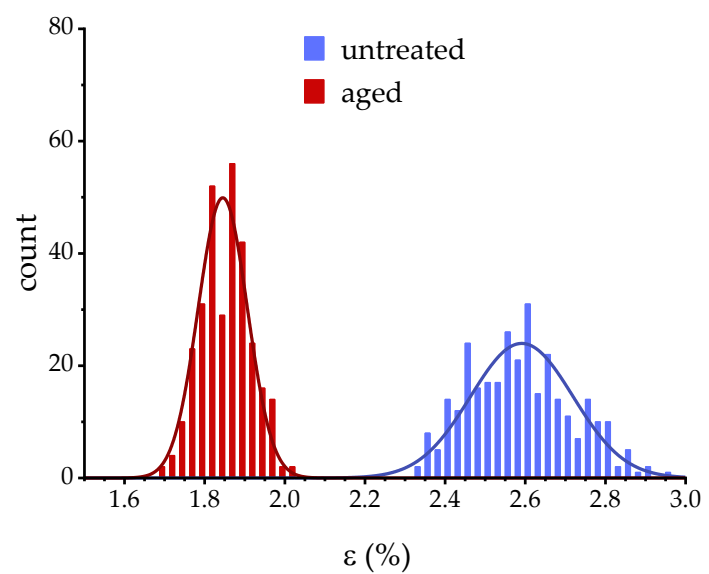

(a)

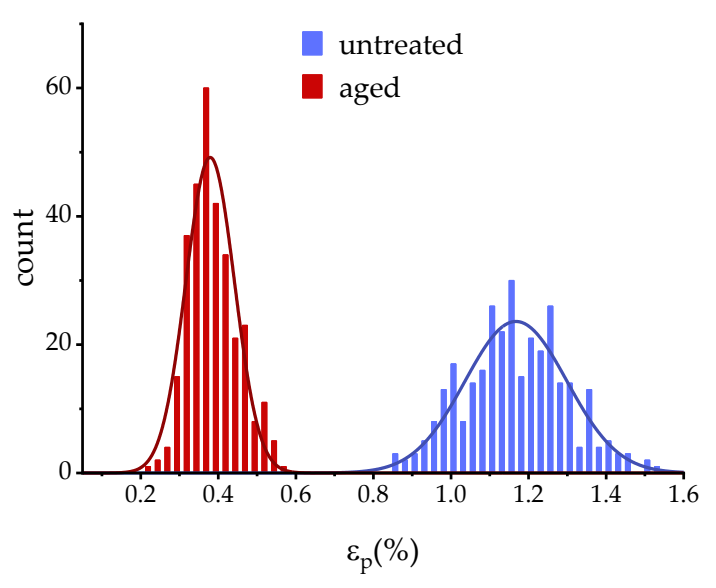

(b)

Figure 5. Histograms of (a) total strain at break and (b) plastic strain at break for Ø3.6C compact steel cord in untreated and $150{ }^{\circ} \mathrm{C} / 45 \mathrm{~min}$ aged conditions

\subsection{Abnormal sequential break of Warrington steel cords}

Force-strain diagrams of $\varnothing 3.6 \mathrm{C}$ compact and $\varnothing 4.5 \mathrm{~W}$ Warrington cords are recorded. Diagrams taken without heat treatment and subsequent to a $45 \mathrm{~min}$ isothermal aging at $150{ }^{\circ} \mathrm{C}$ are compared (Figure 6).

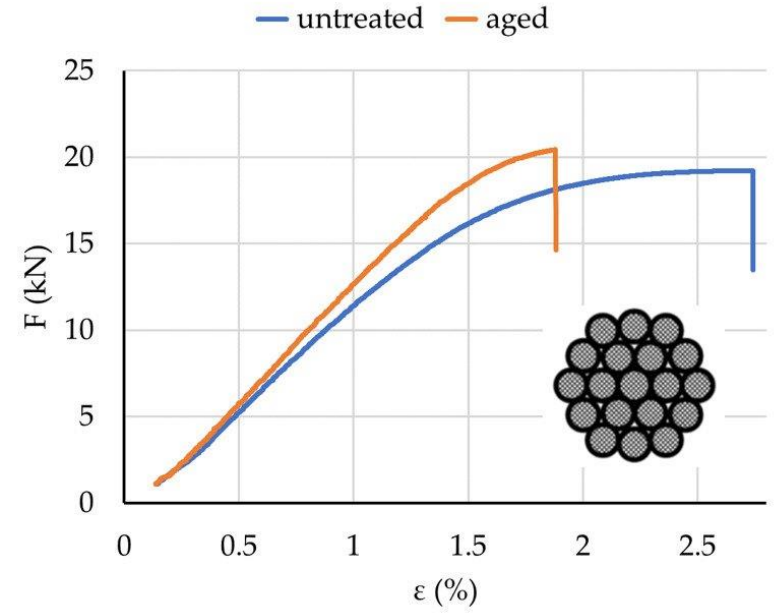

(a)

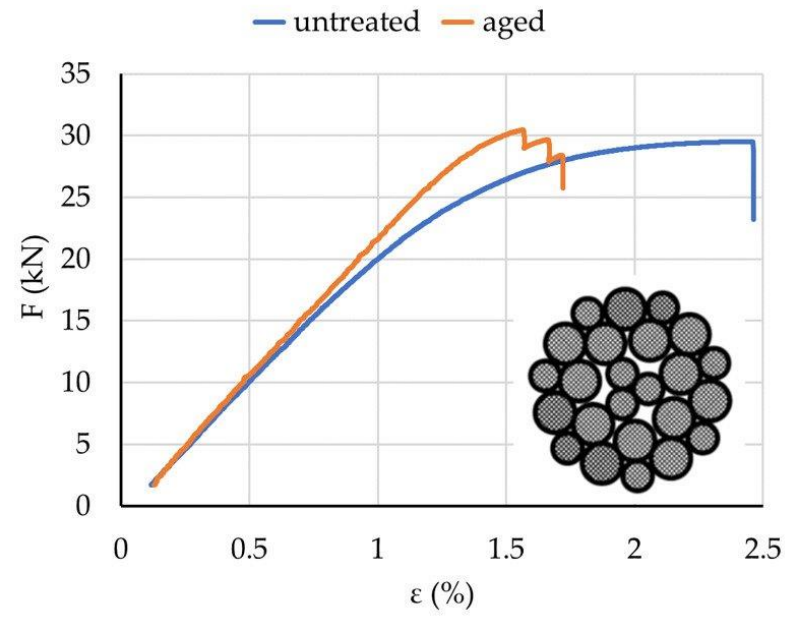

(b)

Figure 6. Typical tensile diagrams in untreated and $150{ }^{\circ} \mathrm{C} / 45 \mathrm{~min}$ aged conditions of (a) Ø3.6C compact type steel cord and (b) $\varnothing 4.5 \mathrm{~W}$ Warrington type steel cord

Typical tensile curve pairs of a Ø3.6C specimens can be seen in Figure 6a. The overall change in the main mechanical properties discussed in previous subsections is apparent. Moreover, a definite breaking point is observed even in aged condition, which indicates that all of the wire components of the strand reach their strain capacity limits at the same time. In other words, the properly balanced load distribution over the individual wire filaments - of mostly the same thickness - remained perfect even if SSA took place. Altogether 315 aged and 315 untreated specimens were tested and all of them provided the same favorably regular failure mode.

On the other hand, in the case of $\varnothing 4.5 \mathrm{~W}$ Warrington type steel cords an irregular break is noticed as the tensile test is performed on previously heat aged pieces (Figure 
$6 \mathrm{~b})$. Out of the tested 76 aged cord specimens $68.4 \%$ presented sequential pre-mature failure, without such occurrences in the untreated 76-element control group.

The aforesaid uncertain load carrying capacity in the inelastic deformation regime is especially disadvantageous in the case of the given high-pressure oil hose reinforcement steel cords. Those flexible pressure vessels contain numerous concentric helically wound steel cord layers with precisely optimized individual lay angles. Cord orientations are accurately calculated in order to reach proper transmission of the loads between the adjacent reinforcement layers. Due to the significant risk level present in the oil \& gas industry, flexible pipe related standards specify high design safety factors. So to fulfill these requirements it is conventional that beside the linearly elastic range the plastic load carrying capacity of the steel plies is also utilized as the minimum burst pressure is calculated. Evidently the revealed adverse failure mode well below the expected total ply strain can have serious consequences if the phenomenon is not handled appropriately.

The anomaly is only experienced in case of Warrington type steel cords. This relatively complex structure comprises 10 plies of $\varnothing 0.68$ wires and 14 plies of $\varnothing 0.91$ wires. It is considered that the early sequential break is caused by the different aging mechanism of the component wires. Hence they are investigated in terms of strength and elongation at break in untreated and $150{ }^{\circ} \mathrm{C} / 45$ min aged conditions. Results can be seen in Table 5 .

Table 5. Mean maximum force and total strain values of $\varnothing 0.68$ and $\varnothing 0.91$ wires in untreated and aged conditions

\begin{tabular}{cccc}
\hline & & $\mathbf{F}_{\max }(\mathbf{N})$ & $\boldsymbol{\varepsilon}(\mathbf{\%})$ \\
\hline \multirow{2}{*}{$\boldsymbol{\varnothing 0 . 6 8}$} & raw & 927 & 2.28 \\
& aged $^{*}$ & 1011 & 1.82 \\
\hline \multirow{2}{*}{$\varnothing \mathbf{0 . 9 1}$} & raw & 1424 & 2.30 \\
& aged $^{*}$ & 1545 & 1.70 \\
\hline
\end{tabular}

* $150{ }^{\circ} \mathrm{C} / 45 \mathrm{~min}$.

Ultimate elongation at break of $\varnothing 0.91$ wires is found to be $0.1 \%$ lower than that of $\varnothing 0.68$ wires. The irregular failure of the Warrington cord that experienced SSA is explained using the following fundamental hypothesis.

A few of the $\varnothing 0.91$ wires-those with coincidentally the lowest strain capacity in aged state-reach their strain limit and get overloaded one by one. Meanwhile the remaining cord structure - especially the 10 plies of $\varnothing 0.68$ wires - are still well below its tensile capacity in terms of overall tensile stress as well as the actual strain.

This hypothesis is confirmed since all the drop sequences in force - similarly as it is displayed in Figure $6 \mathrm{~b}$ - are found to be in the magnitude of $1500 \mathrm{~N}$ similarly to the value of the mean $F_{\max }$ of $\varnothing 0.91$ wires displayed in Table 3.

It is obvious that the cord strength is irreversibly reduced due to the prematurely broken filaments. Furthermore, the sudden loss of balance results in an uncontrolled deformation of the complex strand structure. These two effects ultimately cause rapid failure of the Warrington steel cord well below its theoretical $F_{\max }$.

On one hand considering the given anomaly utilizing compact type steel cords in multi-layer high pressure rubber hoses may be preferable. On the other hand, some resolutions may be also feasible to improve the Warrington steel cords even with the presently used already proven and cost-efficient high-carbon steel grade. Such options require further research on optimization of the cord geometry or the wire drawing procedures, taking into consideration the variation of material performance as SSA takes place.

\section{Conclusions}

The saturation character of SSA on the investigated high-carbon steel wires has been proven in the temperature range $125-200^{\circ} \mathrm{C}$. The relevant ultimate and interim strength 
and strain values have been determined providing a proper basis for further kinetic analyses in detail.

At the typical vulcanization temperature of $150{ }^{\circ} \mathrm{C}$ it has been demonstrated that the material properties after heat aging for $45 \mathrm{~min}$ represents the eventual aged condition of the material. This has been confirmed both in terms of strength as well as elongation parameters within the $125-200{ }^{\circ} \mathrm{C}$ temperature interval.

Quantitative results have been presented for the investigated compact type high-pressure rubber hose reinforcement steel cord. Data have been given based on statistics of a 630-element sample. SSA effects on the most important mechanical characteristics of the plies have been precisely described. A significant rise in force at yield and maximum force has been found along with a drastic plummeting of the strain capacity in the plastic regime.

The premature sequential failure mode of Warrington type steel cords has been revealed as SSA took place. A fundamental explanation of this unfavorable irregular break has been given based on the different character of SSA in the case of the steel wire components that comprise the Warrington type cords.

Severe consequences to engineering applications have been discussed. Some potential resolutions have been highlighted that may solve the reported technical anomaly.

Conflicts of Interest: The authors declare no conflict of interest. Authors identify and declare any personal circumstances or interest that may be perceived as inappropriately influencing the representation or interpretation of reported research results.

\section{References}

1. Qiang, B. , et al. Bonded flexible pipes. In Advances in Pipes and Pipelines Flexible Pipes, 1st ed.; John Wiley \& Sons, Inc.: 11 River Street, Hoboken, NJ 07030, USA, 2017; pp. 357-392.

2. $\quad$ Feyrer K. Wire Ropes, 2nd ed.; Springer: Heidelberg, Germany, 2015; pp. 1-58.

3. Costello G. A. Theory of Wire Rope, 2nd ed.; Springer: New York, USA, 1997; pp. 11-43.

4. Bauschinger J. Variations in the elastic limit of iron and steel. J. Iron and Steel Inst. 1887, 1, 442-444.

5. Cottrell, A.H., and Bilby, B.A. Dislocation theory of yielding and strain ageing of iron. Proc. Physical Soc.1949, 62A, 49-61.

6. Parvin, H.; Kazeminezhad, M. Development a dislocation density based model considering the effect of stacking fault energy: severe plastic deformation. Computational Materials Science 2014, 95, 250-255.

7. Kemp, I. P., et al. Static strain aging in high carbon steel wire. Material Science and Tech. 1990, 6, 331-337.

8. Veiga, R. G. A., et al. Atomistic modeling of carbon Cottrell atmospheres in BCC iron. J. Phys.: Condensed Matter 2013, 25, 7p.

9. Nishimo, K., and Takahashi, K. Strain age hardening in range $150-350^{\circ} \mathrm{C}$ of carbon steel. Trans. of the Japan Inst. of Metals 1962, 3 , $57-62$.

10. Davies, N. P. W. Strain aging in ultra-high strength drawn pearlitic steels. Univ. of the Witwatersrand, Dept. of Metallurgy and Material Eng. 1987, 10.04.1987.

11. Staiger M. P. et al. Multistage strain aging of low-carbon steels. Materials Science and Engineering A 2004, 364, 35-47. 